\title{
Treatment of Laryngotracheal Papilloma with 532-nm Diode Laser
}

Jaehyun Shim

Soo Jeong Choi

Kwang-Yoon Jung

Seung-Kuk Baek

Department of Otorhinolaryngology-Head and Neck Surgery, Korea University, College of Medicine, Seoul, Korea

\section{Correspondence}

Seung-Kuk Baek

Department of Otorhinolaryngology-Head and Neck Surgery, Korea University Anam Hospital, 73 Inchon-ro, Seongbuk-gu, Seoul 02841, Korea Tel.: +82-2-920-6618

Fax: $+82-2-920-5233$

E-mail: mdskbaek@agmail.com

(C) Korean Society for Laser Medicine and Surgery

(c) This is an open access article distributed under the terms of the Creative Commons Attribution NonCommercial License (http://creativecommons.org/ licenses/by-nc/4.0) which permits unrestricted noncommercial use, distribution, and reproduction in any medium, provided the original work is properly cited.

\begin{abstract}
A 45-year-old Korean male with laryngotracheal papilloma was treated using a 532-nm diode laser at six watts with a pulse width of 25 milliseconds. Two months after the laser treatment, the resected region was well-healed without significant scar contracture. This outcome suggests that a 532-nm diode laser can be a safe and effective treatment for laryngotracheal papilloma.
\end{abstract}

\section{Key words}

Laser; Larynx; Trachea; Papilloma 


\section{INTRODUCTION}

Laryngeal papillomatosis is rapidly growing and noninvasive tumors that can also occur in the oral cavity, pharynx, trachea, and lung, and is elicited by human papilloma virus (HPV) infection on laryngeal mucosa.' Presenting symptoms include voice change, stridor, and rarely dyspnea. This disease can occur equally in children and adults, but the clinical course of children is characterized by multiple recurrences after surgical removal for months or years, even if the recurrence rate of laryngeal papilloma is relatively low in adult patients. Severe and advanced laryngeal papilloma can elicit airway obstruction. thus, HPV laryngeal papillomatosis is often referred to as recurrent respiratory papillomatosis.

The many different medical, surgical, and immunological procedures have been used for the treatment of laryngeal papillomatosis. The most common treatments at this time are carbon diaxide (CO2) laser excision or endolaryngeal microdebrider excision through direct laryngoscopy. ${ }^{2-4}$ However, despite the repeated and aggressive treatment, relapses of laryngeal papillomatosis are common. ${ }^{5-7}$

The 585-nm pulsed dye laser (PDL) energy and 532nm potassium-titanyl-phosphate (KTP) laser energy penetrate epithelium without damaging it and is selectively absorbed by the underlying microvasculature. Since laryngeal papillomatosis are benign angiomatous neoplasms with a microvascular core, the previous studies have suggested such angiolytic lasers are feasible to be applied to laryngeal papillomatosis. .-12 $^{-12}$

We report a case of laryngeal and tracheal papillomatosis that was successfully treated by $532-\mathrm{nm}$ diode laser with the same wavelength as KTP laser.

\section{CASE REPORT}

A 45-year-old Korean male suffering from hoarseness was diagnosed with laryngeal papillomatosis in 2005 and underwent 27 laryngeal microsurgeries using microdebrider, CO2 laser, or intralesional cidofovir injection for 10 years. After the last operation, the laryngeal papilloma showed complete remission. However, he visited the hospital again due to a gradual change in his voice and was diagnosed with recurrent laryngeal and tracheal papillomatosis through endoscopy. In the bronchoscope that was performed to evaluate the extent of tracheal lesion and to identify the other lesion of airway, the papilloma of right upper bronchus was found. We decided to treat the laryngeal and tracheal papillomatosis with the laryngeal microsurgery using the CO2 laser (Acublade ${ }^{\mathrm{TM}}$ system; Lumenis, Santa Clara, CA, USA) and the 532-nm diode laser (QUANTA D-8 ${ }^{\circledR}$; Quanta System S.p.A., Solbiate Olona, Italyl and decided to do the cryosurgery for bronchial pap-
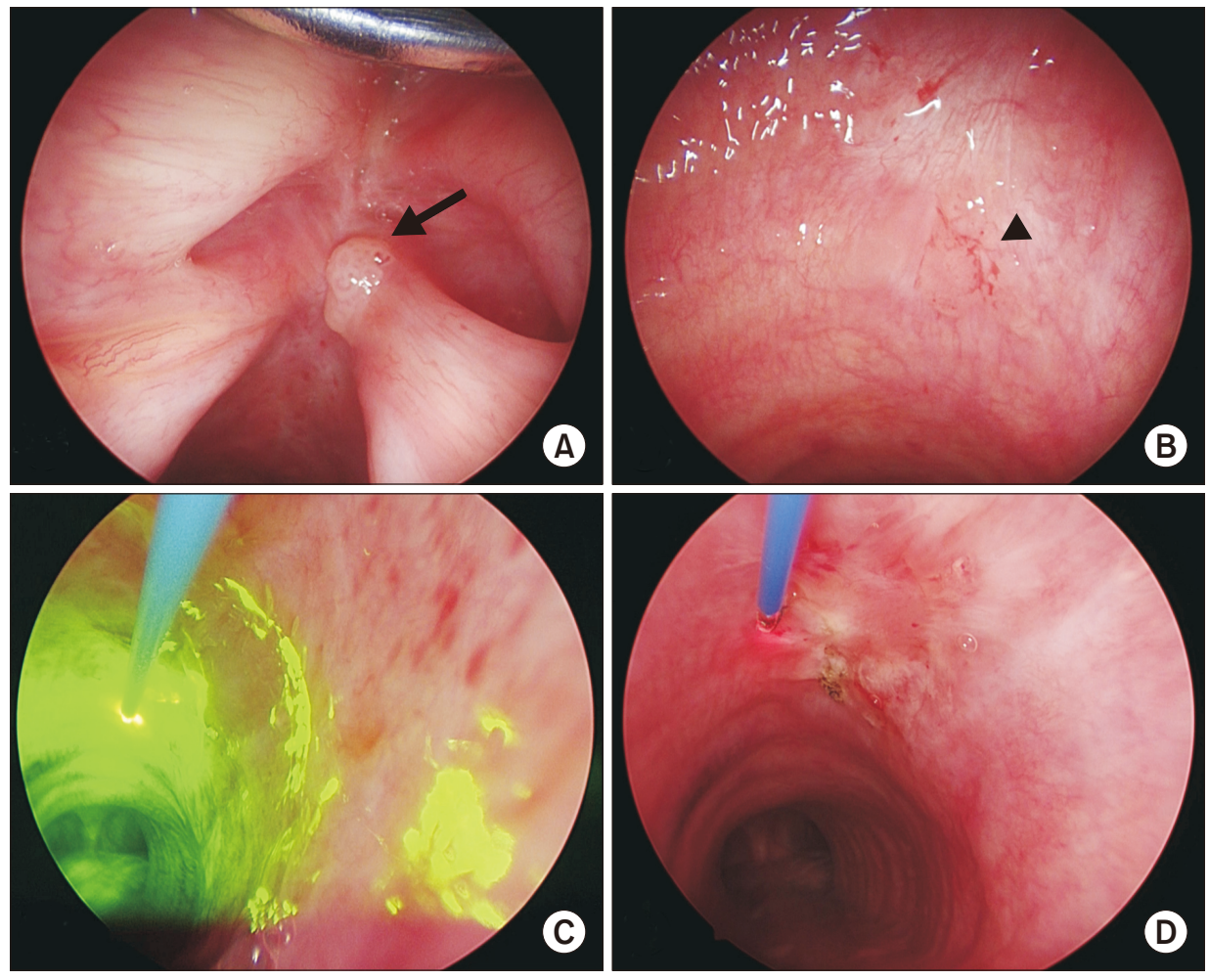

Fig. 1. The endoscopic findings of laryngeal and tracheal papillomatosis. (A) Laryngeal papilloma (arrow), (B) Tracheal papilloma (arrowhead), (C) The irradiation of 532-nm diode laser, (D) Photoablation of mucosa after irradiation. 
illoma by cardiothoracic surgeon.

After general anesthesia, the laryngeal and tracheal lesions were evaluated with 70-degree endoscope (Fig. 1A and $1 \mathrm{~B}$ ). The laryngeal papilloma was removed with $\mathrm{CO} 2$ laser at 5 watts with superpulse mode after irradiation of $532-n m$ diode laser at 6 watts with a pulsed width of 25 milliseconds. In the tracheal papilloma, only the irradiation of 532-nm diode laser was performed under 70-degree endoscope because it was not impossible to use $\mathrm{CO} 2$ laser there (Fig. $1 \mathrm{C}$ ). The treatment end point was visualized blanching of the tracheal mucosa at the time of laser treatment, which is consistent with ischemia secondary to photoablation of vessels of the irradiated lesion (Fig. 1D). After 4 additional operations, the papillomatosis of larynx, trachea and bronchus became complete remission.

\section{DISCUSSION}

The preservation of laryngeal functions such as voice and airway patency as well as the eradication of the tumor are very important in the management of laryngotracheal papilloma. However, the frequent and rapid recurrence characteristics of laryngeal papilloma make its treatment difficult. Furthermore, the repeated operations remain fibrotic scar and glottic web formation, which worsen the voice quality.

To reduce the adjacent normal tissue injury of papilloma, the lasers with various wavelengths including $\mathrm{CO} 2$ laser, 585-nm PDL, and 532-nm KTP laser have been used. ${ }^{3,9-11,13}$ PDL and KTP laser with the similar wavelength are angiolytic lasers that were developed based on the concept of selective photothermolysis, which allows for photocoagulation of microvascular lesions and minimal injury of the surrounding tissues. These angiolytic lasers denatures basement membrane anchoring fibers located in the lamina lucida of the basement membrane through a photoacoustic or photothermal effect and creates a cleavage plane between the epithelium and superficial lamina propria.?

Since human papilloma viruses infect basal cells that is the only dividing cells of the epithelium, it is necessary to remove the entire epithelial layer where the papilloma occurred. To preserve the voice, only a minimal pathological mucosa should be removed. However, the presence of a latent infection of HPV in the normal mucosa around papilloma explains the clinical pattern such as the frequent recurrence after surgical removal of laryngeal papillomatosis. Therefore, these angiolytic lasers that denatures around the basement area of the epithelium can be useful to treat laryngeal papillomas.
The 532-nm diode laser, which has a wavelength similar to that of PDL and KTP laser, is an angiolytic laser that causes photocoagulation of microvasculatures within submucosal area. This inexpensive and easy-to-use diode laser can also be applied in the treatment of laryngeal papillomatosis. In particular, the tracheal papilloma in this case makes it difficult to apply a CO2 laser or microdebrider that does not have access to the tracheal lesion due to the lesion too deep and narrow from the mouth.

Even if surgical treatment is not optimal as a way to treat the disease caused by viruses, the $532-\mathrm{nm}$ diode laser may be useful and feasible for the treatment of laryngotracheal papillomatosis, considering the physiologic mechanism of this angiolytic laser.

There are some limitations for using $532-\mathrm{nm}$ diode laser. Since lights with a wavelength of 532-nm is in the visible light range, the eye protection is very important during irradiating of the lasers. However, subtle treatment effects are poorly visualized through the 532-nm wavelength-specific protective eyewear and there is an inconvenience of removing the eyewear between laser treatments and checking the treatment effect.

\section{CONCLUSIONS}

The 532-nm diode laser may be a useful tool to remove laryngotracheal papillomatosis with minimal collateral tissue damage through the photocoagulation of microvascular structure around basement membrane.

\section{ACKNOWLEDGEMENTS}

This research was supported by the Clinical Trial Center of Korea University Anam Hospital (11502411), the Korea Health Technlogy R\&D Project (HI14C0748) through the Korea Health Industry Development Institute (KHIDI) by the Ministry of Health \& Welfare, and the Basic Science Research Program through the National Research Foundation of Korea funded by the Ministry of Education (NRF2016R1D1A1A02937362, NRF-2018R1D1A1A09083263).

\section{CONFLICT OF INTEREST}

None.

\section{REFERENCES}

1. Steinberg BM, Topp WC, Schneider PS, Abramson AL. Laryngeal papillomavirus infection during clinical remission. N Engl J Med 1983;308:1261-4. 
2. Strong MS, Jako GJ, Polanyi T, Wallace RA. Laser surgery in the aerodigestive tract. Am J Surg 1973;126:529-33.

3. Strong MS, Vaughan CW, Cooperband SR, Healy GB, Clemente MA. Recurrent respiratory papillomatosis: management with the CO2 laser. Ann Otol Rhinol Laryngol 1976;85:508-16.

4. Ford CN. Advances and refinements in phonosurgery. Laryngoscope 1999;109:1891-900.

5. Schuurman AM, Van Den Broek P. Results of treatment with alpha-interferon in adult-onset laryngeal papillomatosis. Clin Otolaryngol Allied Sci 1986;11:447-53.

6. Leventhal BG, Kashima HK, Mounts P, Thurmond L, Chapman S, Buckley $S$, et al. Long-term response of recurrent respiratory papillomatosis to treatment with lymphoblastoid interferon alfa-N1. Papilloma Study Group. N Engl J Med 1991;325:613-7.

7. Snoeck R, Wellens W, Desloovere C, Van Ranst M, Naesens L, De Clercq E, et al. Treatment of severe laryngeal papillomatosis with intralesional injections of cidofovir [(S)-1-(3-hydroxy2-phosphonylmethoxypropyl)cytosine]. J Med Virol 1998;54:21925.

8. Bower CM, Waner M, Flock S, Schaeffer R. Flash pump dye laser treatment of laryngeal papillomas. Ann Otol Rhinol Laryngol 1998;107:1001-5.
9. Franco RA Jr, Zeitels SM, Farinelli WA, Anderson RR. 585-nm pulsed dye laser treatment of glottal papillomatosis. Ann Otol Rhinol Laryngol 2002;111:486-92.

10. Zeitels SM, Akst LM, Burns JA, Hillman RE, Broadhurst MS, Anderson RR. Office-based 532-nm pulsed KTP laser treatment of glottal papillomatosis and dysplasia. Ann Otol Rhinol Laryngol 2006;115:679-85.

11. Burns JA, Zeitels SM, Akst LM, Broadhurst MS, Hillman RE, Anderson R. $532 \mathrm{~nm}$ pulsed potassium-titanyl-phosphate laser treatment of laryngeal papillomatosis under general anesthesia. Laryngoscope 2007;117:1500-4.

12. Xie X, Young J, Kost K, McGregor M. KTP 532 nm laser for laryngeal lesions. A systematic review. J Voice 2013;27:245-9.

13. Tan OT, Hurwitz RM, Stafford TJ. Pulsed dye laser treatment of recalcitrant verrucae: a preliminary report. Lasers Surg Med 1993;13:127-37.

How to cite this article: Shim J, Choi SJ, Jung KY, Baek SK. Treatment of laryngotracheal papilloma with 532-nm diode laser. Med Lasers 2020;9:190-193. https://doi.org/10.25289/ ML.2020.9.2.190 